\title{
Noninvasive Localization of Petroleum-derived Spray Oil in Plants with Chemical Shift Selective Magnetic Resonance Imaging
}

B.L. Tan, ${ }^{1}$ N. Reddy, ${ }^{2}$ V. Sarafis, ${ }^{1,3}$ G.A.C. Beattie, ${ }^{1}$ and R. Spooner-Hart ${ }^{1}$ Centre for Horticulture and Plant Sciences, University of Western Sydney, Locked Bag 1797, Penrith South Distribution Centre, New South Wales 1797, Australia

Additional index words. petroleum-derived spray oil, localization, NMR spectroscopy, MRI, chemical shift selective image

\begin{abstract}
Nuclear magnetic resonance (NMR) spectroscopy and magnetic resonance imaging (MRI) were used to detect petroleum-derived spray oils (PDSOs) in citrus seedlings and trees. The NMR spectrum of the phantom containing $10 \%(\mathrm{v} / \mathrm{v})$ of a $n \mathrm{C} 24$ agricultural mineral oil (AMO) showed the resonance of the water protons at $\delta \approx 5 \mathbf{p p m}$, while the resonance of the oil protons at $\delta=1.3$ to $1.7 \mathrm{ppm}$. The peak resolution and the chemical shift difference of more than $3.3 \mathrm{ppm}$ between water and oil protons effectively differentiated water and the oil. Chemical shift selective imaging (CSSI) was performed to localize the AMO within the stems of Citrus trifoliata $\mathrm{L}$. seedlings after the application of a $4 \%$ (v/v) spray. The chemical shift selective images of the oil were acquired by excitation at $\delta=1.5 \mathrm{ppm}$ by averaging over 400 transients in each phase-encoding step. Oil was mainly detected in the outer cortex of stems within $10 \mathrm{~d}$ of spray application; some oil was also observed in the inner vascular bundle and pith of the stems at this point. CSSI was also applied to investigate the persistence of oil deposits in sprayed mature Washington navel orange (Citrus $\times$ aurantium L.) trees in an orchard. The trees were treated with either fourteen $0.25 \%$, fourteen $0.5 \%$, four $1.75 \%$, or single $7 \%$ sprays of a $n \mathrm{C} 23$ horticultural mineral oil (HMO) 12 to 16 months before examination of plant tissues by CSSI, and were still showing symptoms of chronic phytotoxicity largely manifested as reduced yield. The oil deposits were detected in stems of sprayed flushes and unsprayed flushes produced 4 to 5 months after the last spray was applied, suggesting a potential movement of the oil via phloem and a correlation of the persistence of oil deposit in plants and the phytotoxicity. The results demonstrate that MRI is an effective method to probe the uptake and localization of PDSOs and other xenobiotics in vivo in plants noninvasively and nondestructively.
\end{abstract}

Petroleum-derived spray oils (PDSOs) have been widely used for about a century to control a range of phytophagous arthropod pests, with most use focusing on the control of mites and scales in horticultural crops (Agnello, 2002; Davidson et al., 1991; Ebeling, 1950; Riehl, 1969). They have several advantages over synthetic pesticides, including negligible health and environmental effects, limited disruption of natural enemy activity and no empirically demonstrated resistance by pests (Beattie et al. 2002). They are also as effective as many broad-spectrum synthetic pesticides against susceptible pests (Grossman, 1990; Davidson et al. 1991). Contemporary PDSOs known as horticultural mineral oils (HMOs) and agricultural mineral oils (AMOs) are key components of integrated pestmanagement(IPM) programs, particularly citrus IPM programs (Davidson et al., 1991; Smith et al., 1997; Rae et al., 2000,

Received for publication 8 Dec. 2004. Accepted for publication 11 Dec. 2004.

${ }^{1}$ Author to whom correspondence and reprints should be addressed. Present address: Biocontrol Technologies, AgResearch, P.O. Box 60 Lincoln, Canterbury, New Zealand; e-mail binglin. tan@agresearch.co.nz.

${ }^{2}$ NMR and MRI Facility.

${ }^{3}$ School of Life Sciences University of Queensland.
Beattie et al., 2002; Huang et al., 2002).

Since the early 1900 s it has been unequivocally established that PDSOs can induce acute and chronic phytotoxicity in citrus (Ebeling, 1950; Riehl, 1969). Acute symptoms are manifested as burns and necrotic lesions of young leaves and meristems, and accelerated abscission of green leaves and fruit, and chronic symptoms are expressed as reduced yield and fruit quality, alternate cropping, delayed fruit maturation and disruption of plant metabolism. The causes are well understood (Hodgkinson et al., 2002). Acute phytotoxicity is primarily associated with cell death due to the disruption to cell membranes by acidic compounds that may occur naturally in oils, and acidic compounds formed by oxidation of unsaturated molecules in the oils. Chronic effects are generally related to disruption of plant metabolism by higher-molecular weight unsaturates, acidic compounds formed by these unsaturates and unstable saturated compounds in the oil, and interference with transpiration, respiration, photosynthesis, plant growth regulation and other functions by saturated molecules (Ebeling, 1950; Hodgkinson et al., 2002; Johnson et al., 2002; Knight et al., 1929).

The effects of PDSOs on plants are closely related to the persistence of oil molecules on and in the sprayed plants, with the risk of phy- totoxicity increasing with increasing persistence and amounts of oil deposited. However, despite their importance in inducing phytotoxicity the manner of movement and localization of PDSO molecules in plant tissues have been largely ignored since Knight etal.(1929), Young (1934, 1935, 1941), Young and Morris (1933), and Rohrbaugh(1934,1941)investigated movement of PDSO into and within plants using lipophilic stains and light microscopy. Recent studies, for example the use of fluorescence spectroscopy by Furness et al. (1988) and Fourier transform infra-red (FTIR) spectroscopy by Hodgkinson et al. (1996) and Johnson et al. (2002b), have only focused on measuring surface deposits shortly after application of sprays. Fluorescence spectroscopy is not suitable for determining deposits within tissues and restrictions on the use of Freon and $\mathrm{CCl}_{4}$ have largely rendered FTIR impractical for measuring both surface and internal deposits. Considerable effort has been made during the past few years in our laboratory to visualize the localization and movement of AMO and HMO in plants. The techniques employed include fluorescence and confocal microscopy reported elsewhere(Tan, 2004; Tan et al., 2005), and magnetic resonance imaging (MRI) as presented in this paper.

Nuclear magnetic resonance (NMR), and magenetic resonance imaging(MRI) are becoming a powerfulmeans of research in plant science since the 1980s due to their nondestructive and noninvasive features in nature (Callaghan et al., 1994; Faust et al., 1997; MacFall et al., 1991; Metzler etal., 1995). In particular, the combination of NMR spectroscopy with chemical shift selection provides a valuable measurement of the spatial distribution of specific histochemistry of plant materials within a heterogeneous sample (Chudek and Hunter, 1997; Metzelar et al., 1995). Chemical shift selective imaging (CSSI) has been applied to localise and quantify metabolites such as carbohydrates and aromatics (Gersbach and Reddy, 2002; Halloin et al., 1993; Pope, 1991; Pope et al., 1993; Rumpel and Pope, 1992; Sarafis et al., 1990; Tse et al., 1996; Xia and Jelinski, 1995), water transport (Xia and Callaghan, 1992; Zimmerman et al., 1993) and uptake of xenobiotics (Rollins et al., 1989) in plants with high sensitivity.

The chemistry of PDSOs is well understood (Agnello, 2002). PDSOs consist primarily of hydrocarbons. The principal components in contemporary horticultural and agricultural mineral oils (HMOs and AMOs) are saturated isoparaffins, cycloparaffins, and, in most products, aromatics (Agnello, 2002; Davidson et al., 1991), which makes it possible to acquire the chemical shift selective image of oil protons in plants. In this paper we describe the potential of chemical-shift selective MRI technique to determine the localization and persistence of PDSOs within plants after application of sprays. Citrus seedlings and mature trees, a $n \mathrm{C} 24 \mathrm{AMO}$ and $n \mathrm{C} 23 \mathrm{HMO}$ were used for the experiments reported here.

\section{Materials and methods}

Instrumentation. MRI experiments were performed on a spectrometer(UNITY-plus 300 


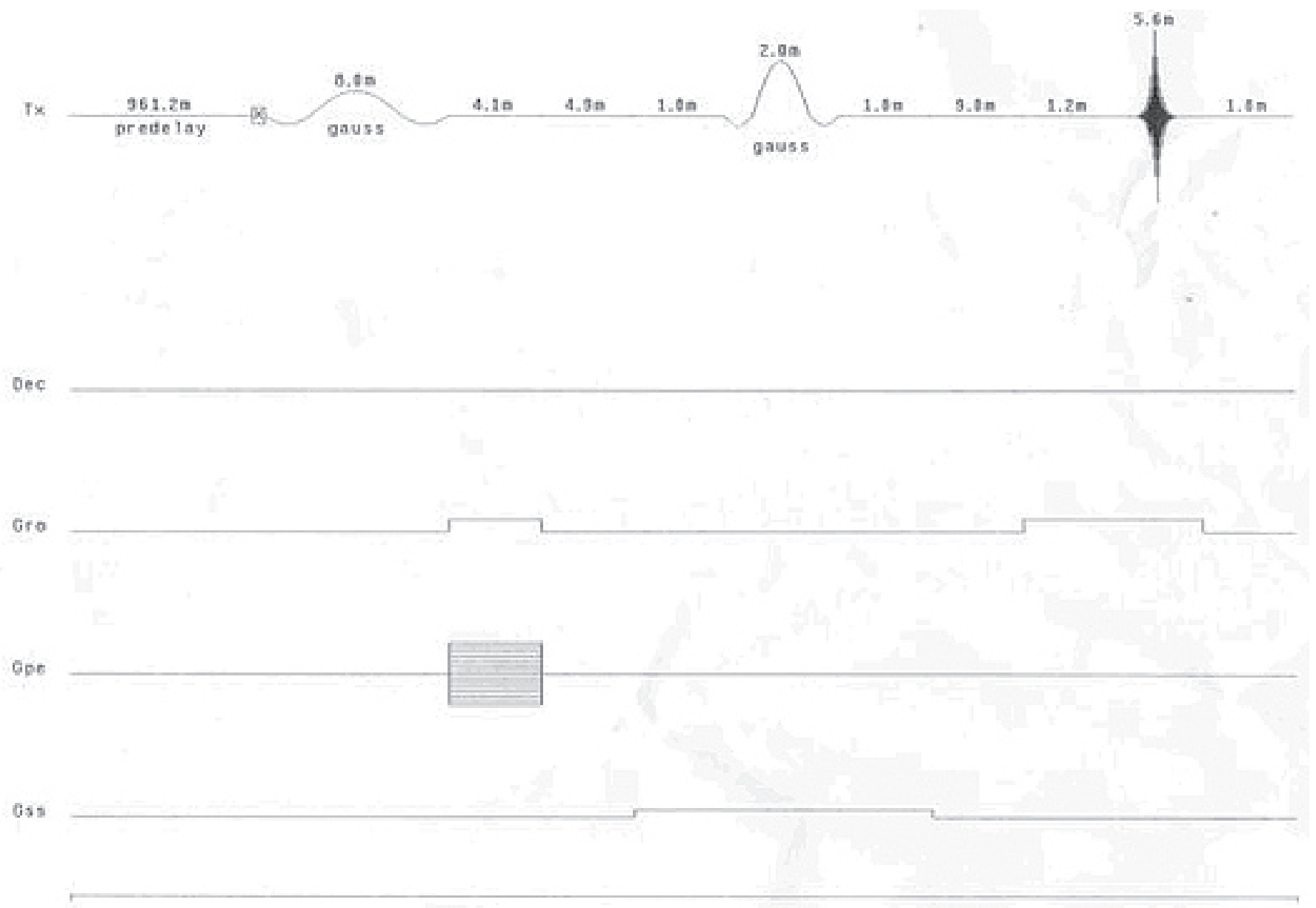

Fig. 1. Chemical shift selective imaging (CSSI) pulse sequence used for generating nuclear magnetic resonance (NMR) images. Details of the pulse are given in the following sections.

NMR; Varian Inc., Polo Alto, Calif.) equipped with a superconducting magnet (7.05 Tesla), with 89 -mm-diameter wide-bore magnet system (Oxford Instruments, Palo Alto). This system is equipped with a micro-imaging accessory. The field gradient coils built into the microimaging probe (Doty Scientific Inc., Columbia, S.C.) head were capable of achieving gradients of up to 50 Gauss $(\mathrm{G}) \cdot \mathrm{cm}^{-1}$ with rise and fall times $<100 \mu \mathrm{s}$.

Two-dimensional chemical shift selective data were collected using CSSI pulse sequence sketched in Fig. 1.

Phantom experiment of petroleum-derived spray oil. A phantom experiment was conducted to differentiate the chemical shift selective spectra of water and petroleum-derived spray oil. The base oil of a commercial saturated AMO ( $n$ C24 SK Enspray 99; SK Corp., Seoul, Korea) with a $\geq 99.8 \%$ unsulfonated residue (UR) value (see Beattie et al., 2002) was used for the experiment. The phantom sample consisted of two 5-mm-diameter glass tubes. One tube was filled with water and another contained $10 \%$ of the base oil dissolved in $\mathrm{CCl}_{4}$ (BDH Laboratory Supplies, Poole, U.K.). The tubes were placed in a standard 30-mm-diameter MRI tube.

The ${ }^{1} \mathrm{H}-\mathrm{NMR}$ spectrum showing chemical shifts of the phantom sample was acquired using the imaging probe with a $30-\mathrm{mm}$ RF coil. The repetition time for the ${ }^{1} \mathrm{H}$ experiment on the sample was $14 \mathrm{~s}$ to allow complete recovery of both the water and oil resonances. The NMR signal obtained from the phantom experiment was used as the reference for water and oil in both phantom and plant imaging experiments.

A nonselective imaging experiment, which produced spatial distributions of both water and oil protons, was conducted by using

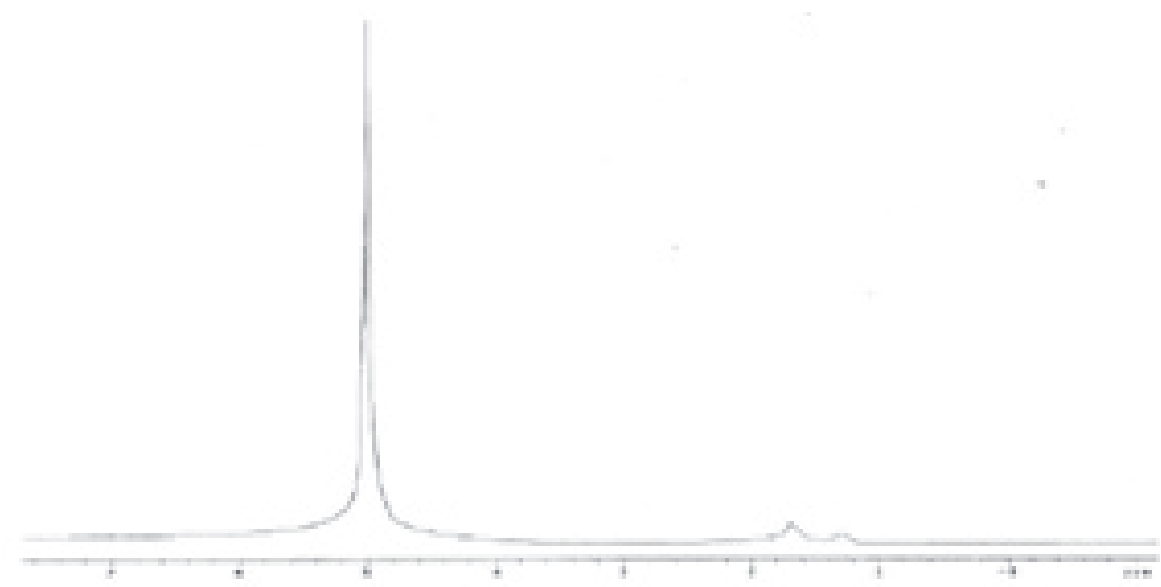

Fig. $2 .{ }^{1} \mathrm{H}-\mathrm{NMR}$ spectrum showing chemical shifts within the phantom containing water and $10 \% \mathrm{v} / \mathrm{v} n \mathrm{C} 24$ $\mathrm{AMO}$ in $\mathrm{CCl}_{4}$. The signal at $\delta \approx 5 \mathrm{ppm}$ arises from water protons, and signals at $\delta \approx 1.3$ and $1.7 \mathrm{ppm}$ arise from the aliphatic protons of the AMO. No signal from aromatic protons, which generally appear at $\delta \approx 6$ to $9 \mathrm{ppm}$, was detected as the AMO contains undetectable traces of these molecules. 
$90^{\circ}$ Gaussian shaped excitation pulse of $8 \mathrm{~ms}$ duration and $400 \mathrm{~Hz}$ bandwidth, and a slice selective $180^{\circ}$ Gaussian shaped refocusing pulses of $2 \mathrm{~ms}$ duration and $800 \mathrm{~Hz}$ bandwidth were employed. The frequency and bandwidth of the first $90^{\circ}$ Gaussian pulse were adjusted to selectively excite the oil signal. Gradient strengths were $10 \mathrm{G} \cdot \mathrm{cm}^{-1}$ for the slice selection and $30 \mathrm{G} \cdot \mathrm{cm}^{-1}$ for the readout and phase
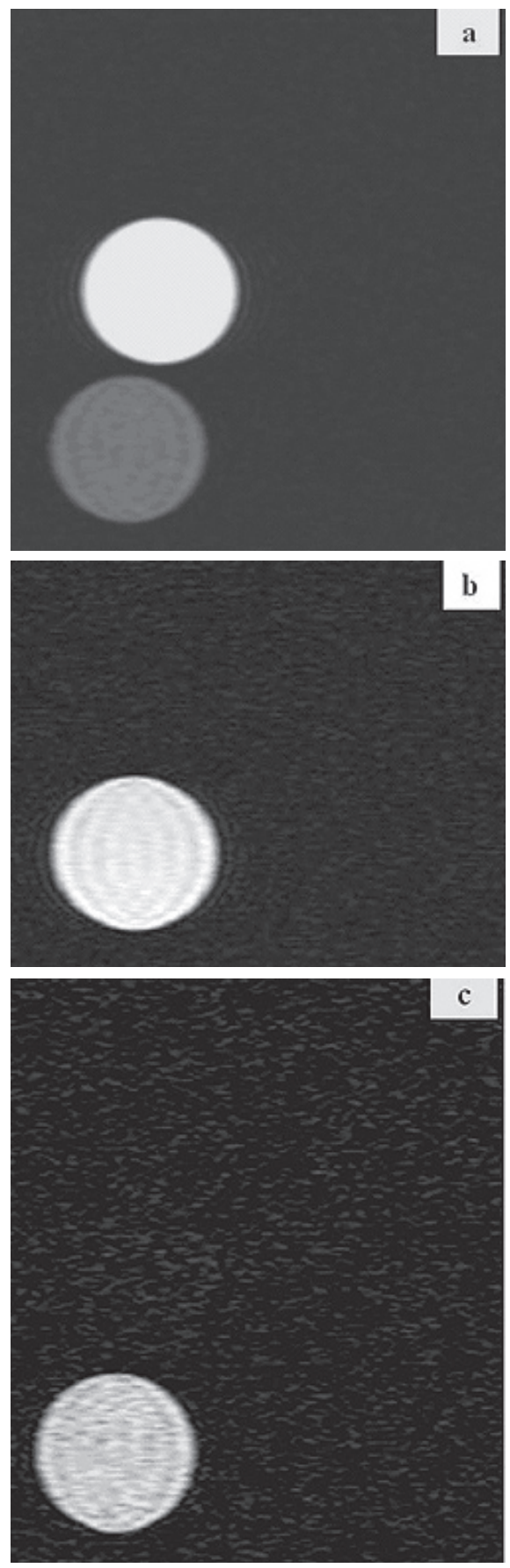

Fig. 3. Proton images of the AMO phantom using a standard two-dimensional imaging sequence. (a), nonselective image. The top image is of a tube containing water, while the image below it is of a tube containing $10 \% \mathrm{AMO}$ in $\mathrm{CCl}_{4}$. (b), chemical shift selective image of water. The frequency of chemical shift selective pulse was at $\delta \approx 5$ ppm. (c), chemical shift selective image of the AMO. The frequency of chemical shift selective pulse was centred at $\delta \approx 1.5 \mathrm{ppm}$. Slice thickness $=3 \mathrm{~mm}$. encoding gradients. The spin-echo time was $30 \mathrm{~ms}$ and the repetition time $1.0 \mathrm{~s}$, and 16 scans were averaged at each phase encoding step. Chemical shift selective images of $3 \mathrm{~mm}$ transverse slices across the water and oil tube were obtained respectively.

Citrus seedling experiment. One-year-old Citrus trifoliata L. seedlings supplied by a commercial nursery (AT Eyles and Sons, Kenthurst, New South Wales (NSW), Australia) were used for the experiment. Initially, about 150 to 200 seedlings were planted in a $30-\mathrm{cm}$-diameter plastic pot. They were 15 to $20 \mathrm{~cm}$ high and 15 to $20 \mathrm{~mm}$ in diameter at the base of stems. Ten (10) relatively uniform seedlings 20 to $22 \mathrm{~cm}$ high and 24 to $30 \mathrm{~mm}$ in diameter were selected and transferred individually to single $15 \mathrm{~cm}$ pots containing Grow Mix-General Open medium (Debco, Berkshire Park, NSW). 5 g Osmocote Plus controlled-release fertilizer (Scotts, Marysville, Ohio; Australian distributor, Northern Rivers Rural Buying Service, South Lismore, NSW) were added to each pot. The seedlings were maintained in a glasshouse at ambient temperature, and spray-irrigated three times every day, for $15 \mathrm{~min}$ on each occasion. The experiments were conducted from December 2002 to January 2003; the average maximum and minimum temperature during this period were 35.6 and $15.5^{\circ} \mathrm{C}$, respectively.

$20 \mathrm{~mL}$ of $4 \% \mathrm{v} / \mathrm{v}$ oil-in-water emulsion of $n$ C24 SK Enspray 99 were sprayed on each seedling using a paint airbrush sprayer (model VSL-SET; Paasche Airbrush Co., Harwood Heights, Ill.) operating at $138 \mathrm{kPa}$ and a distance of 10 to $15 \mathrm{~cm}$ from the target surfaces. NMR spectroscopy and imaging experiments were conducted to determine the distribution of the oil in the stems of the sprayed seedlings $1,3,5$, and $10 \mathrm{~d}$ after the application of spray to assess the distribution of oil in the tissues. For each time sequence, one seedling was randomly chosen. One current spring flush growth was excised, and all the leaves on the growth were removed. One 6-cm-long portion of the stem was cut from the proximal end (base) of the flush growth. The cut stem was painted with silicone grease (Zapfenfett $20 \mathrm{~mL}$; Eppendorf, Cambridge, U.K.) on its surface, and the cut edges were sealed by $2 \%$ $\mathrm{w} / \mathrm{v}$ agar so as to prevent water in tissue from evaporating during the experiment. The stem was then placed vertically in a $10 \mathrm{~mm}$ diameter glass MRI tube after a small wad of wet tissue paper was placed at the base of the tube. The top and bottom of tube was sealed with Teflon tape (DuPont Corp., Wilmington, Del.).

Experiments were conducted to acquire a ${ }^{1} \mathrm{H}-\mathrm{NMR}$ spectrum and transverse slices of both nonselective and chemical shift selective magnetic resonance images. The nonselective images were acquired using SEMS pulse sequence to mainly obtain the distribution of both water and the oil in stems and hence the shape of the stem tissues. Chemical shift selective images of oil were acquired using CSSI pulse sequence to select oil signals and localize the oil within the sprayed stems. The imaging experiments were performed on the spectrometer system described above. SEMS images were acquired with 2-mm transverse slices across the stems and chemical shift selective images with 3-mm transverse slices. The repetition time and the echo time for all images were $1 \mathrm{~s}$ and $3 \mathrm{~ms}$ respectively. SEMS experiments were acquired with 64 scans and CSSI experiments with 400 scans averaged at each of the phase encoding steps.

Citrus tree experiment. This experiment examined the persistence of oil deposits in mature citrus trees as part of a larger field experiment conducted from 2000 to 2001 . In the larger experiment, the phytotoxicity of different spray programs of a $n \mathrm{C} 23$ horticultural mineral oil (Ampol Summer Spray Oil; Caltex Australia Pty Ltd) with a 94\% UR value to mature Washington navel orange (Citrus $\times$ aurantium L.) trees, each about $3.5 \mathrm{~m}$ in height, in an orchard at the University of Western Sydney Hawkesbury campus (Richmond, NSW: $33^{\circ}$ $\left.62^{\prime} \mathrm{S}, 150^{\circ} 75^{\prime} \mathrm{E}\right)$. It was observed that severe leaf/fruit drop, reduction of yield, degraded fruit quality and retardation of maturation, and reduction of flowering in 2000 were associated with the spray programs comprising fourteen $0.25 \%$, single $7 \%$, four $1.75 \%$, and fourteen $0.5 \%$ sprays applied during summer and autumn 2000 . Furthermore, the fruit development in 2001 on trees of these spray programs was significantly suppressed (see Tan, 2004). In order to identify links between oil deposits in plants with the detrimental effects, NMR imaging experiments were performed during April to June 2001 to determine the distribution of oil deposits in the trees. Sprayed 1999 spring flushes, and unsprayed 2000 spring flushes (produced on the 1999 spring flushes 5 to 6 months after the last sprays were applied) were excised from all treatment trees. ${ }^{1} \mathrm{H}-\mathrm{NMR}$ spectrum was first performed to qualitatively analyse the deposition of oil within the stems offlushes, followed by SEMS and CSSI experiments for typical samples using the methods described above. Due to the fact that one CSSI image needed at least $14 \mathrm{~h}$, only one experiment of SEMS and CSSI was performed for each treatment. Experiments were conducted from April to June 2001.

\section{Results}

Phantom sample of petroleum-derived spray oil. The ${ }^{1} \mathrm{H}-\mathrm{NMR}$ spectrum of the $n \mathrm{C} 24$ AMO phantom obtained using a Doty micro-imaging probe is shown in Fig. 2. Three main signals are evident from the spectrum. Resonance from water protons appears at $\delta$ $\approx 5$ ppm, while the signals at $\delta \approx 1.3$ and 1.7 ppm derive from the aliphatic protons of the oil. The oil contains virtually no (undetectable traces) aromatic protons that generally produce resonances at $\delta \approx 6$ to $9 \mathrm{ppm}$. Adetailed analysis of assignment of the signals from the oil was not conducted in this study. The difference of $>3.3 \mathrm{ppm}(\approx 1 \mathrm{kHz})$ in chemical shift between water and the oil enables effective separation of oil from water, and hence is very good for testing the chemical shift selective imaging pulse sequence employed in this study.

The images in Fig. 3a are nonselective, and represent water and the oil distribution. 

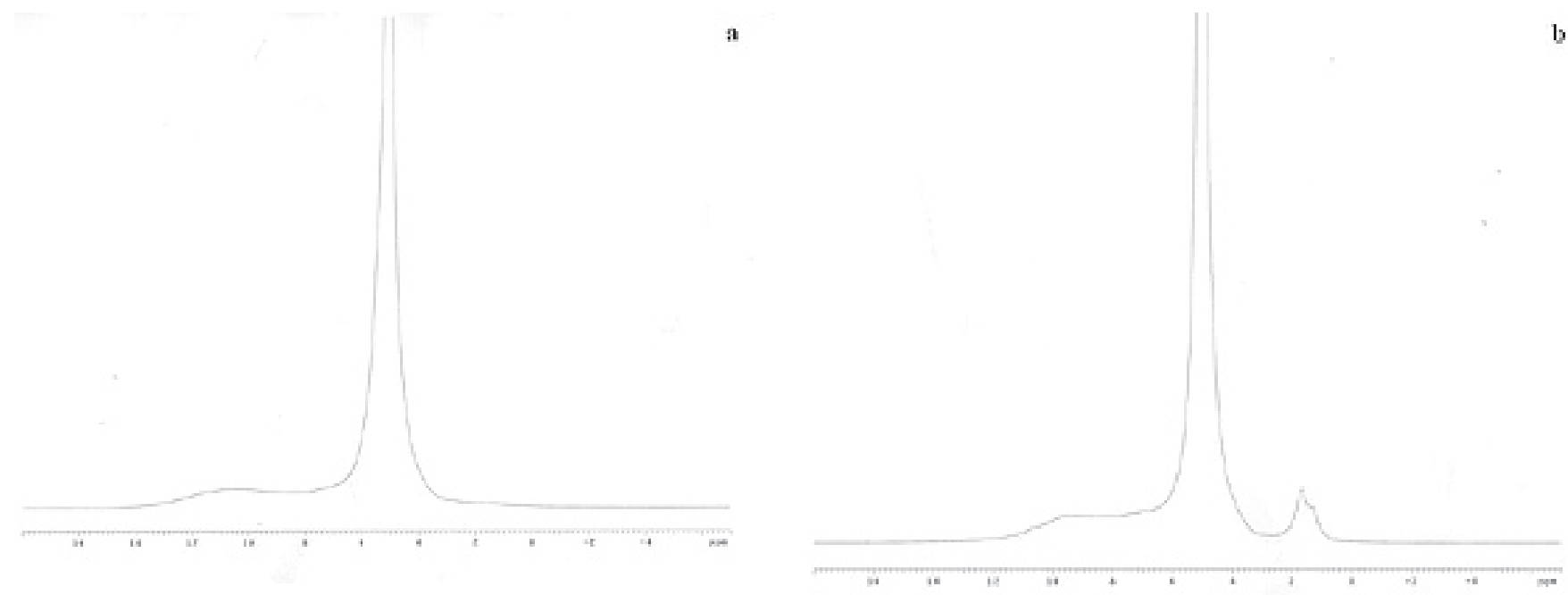

Fig. 4. ${ }^{1} \mathrm{H}-\mathrm{NMR}$ spectra of an unsprayed stem (a) and a $4 \%(\mathrm{v} / \mathrm{v}) n \mathrm{C} 24 \mathrm{AMO}$-sprayed stem (b). The signal at $\delta \approx 5.0$ ppm in both $\mathbf{a}$ and $\mathbf{b}$ derives from water in the tissue. The signals at $\delta \approx 1.3$ and $1.7 \mathrm{ppm}$ in $\mathbf{b}$ arise from the aliphatic proton of the AMO, while no such signals were observed in the unsprayed stem (a). Vertical axes indicate the intensity in arbitrary units set to the same scale for both spectra.

Figure $3 \mathrm{~b}$ and $\mathrm{c}$ show the chemical shift selective images of water and the oil, respectively. Difference of brightness between the two chemical shift selective images (Fig. 3b and c) arises from the difference of spatial proton density distribution of water $(100 \%)$ and the oil $(10 \%)$ in samples in the phantom.

Citrus seedling experiment. Having demonstrated that the high quality proton images could be selectively acquired for the oil phantom sample, MRI was used to selectively observe the localisation of the oil sprayed on plants. First, ${ }^{1} \mathrm{H}-\mathrm{NMR}$ spectra from an unsprayed stem, and a sprayed stem excised $1 \mathrm{~d}$ after spray application, were compared (Fig. 4). The signals from the oil protons appeared at about $\delta \approx 1.3$ and $1.7 \mathrm{ppm}$, thus matching our observations in the phantom experiment, while no signal at $\delta \approx 1.3$ or $1.7 \mathrm{ppm}$ was observed from the unsprayed stem. Second, CSSI of the unsprayed and sprayed stem were performed. No chemical shift selective image of oil was observed from the unsprayed stem. The nonselective and chemical shift selective images of sprayed stems 1,5 , and $10 \mathrm{~d}$ after spray application are shown in Fig. 5. The images on the left column represent the nonselective images of the stems, and those on the right column are the corresponding chemical shift selective images of the oil in the stems. These indicate that $1 \mathrm{~d}$ after application the oil was largely distributed in the outer cortex of stem; $5 \mathrm{~d}$ after application the oil was present in the inner cortex, phloem and cambium of stem, and at the same time the oil in the outer cortex appeared to dissipate. The distribution of oil $10 \mathrm{~d}$ after application displayed a similar pattern to the $5 \mathrm{~d}$ result, but some oils appeared to have entered the xylem and pith. This series of images clearly demonstrates the distribution of the oil in the stems as a function of time.

Citrus tree experiment. The ${ }^{1} \mathrm{H}-\mathrm{NMR}$
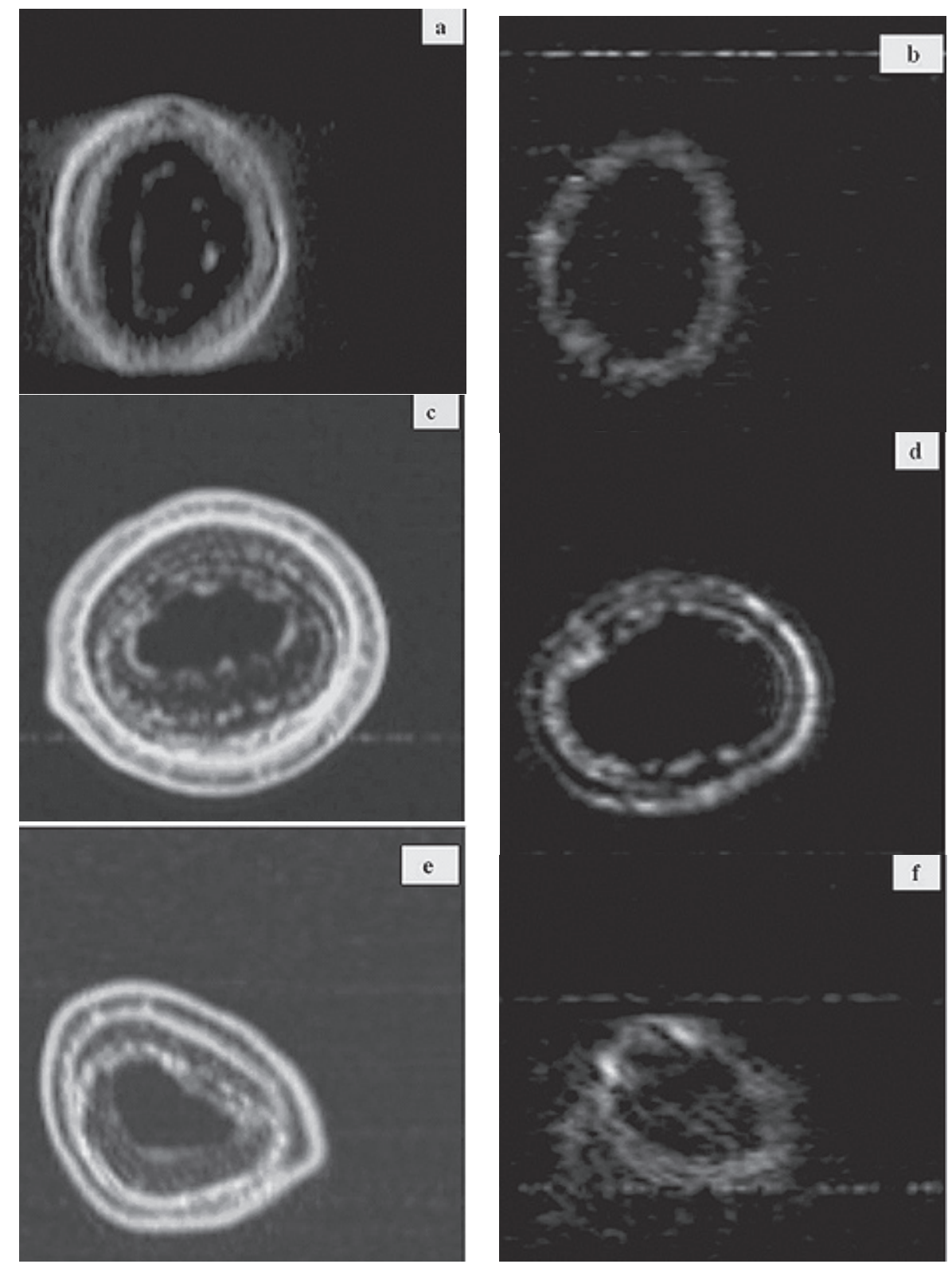

Fig. 5. Nuclear magnetic resonance images of citrus seedling stems $1 \mathrm{~d}(\mathbf{a}$ and $\mathbf{b}), 5 \mathrm{~d}(\mathbf{c}$ and $\mathbf{d})$ and $10 \mathrm{~d}$ (e and f) after spray application of $4 \%(\mathrm{v} / \mathrm{v}) n \mathrm{C} 24 \mathrm{AMO}$ emulsion. The images on left column are the nonselective images and the images on right column are the corresponding chemical shift selective images of the oil in the stems. Images are $3-\mathrm{mm}$ slice thickness, repetition time $=1 \mathrm{~s}$ and echo time $=30 \mathrm{~ms}$ in all cases. 

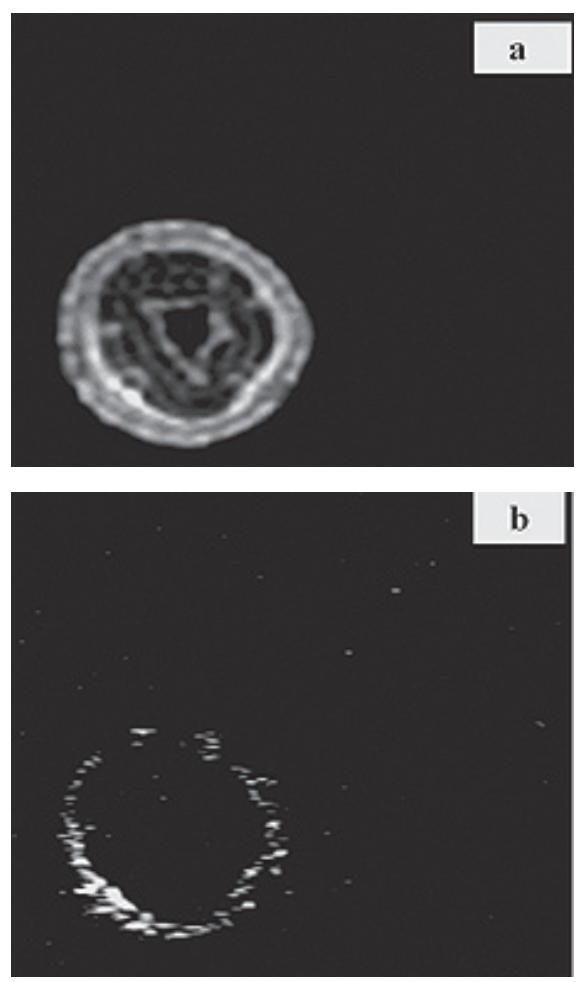

Fig. 6. The nonselective (a) and the corresponding chemical shift selective images (b) of a stem segment of a 1999s spring flush from a navel orange tree sprayed with single $7.0 \% \mathrm{HMO} 12$ to 16 months previously, showing a distribution of mineral oil in outer tissues of the stem to which oil sprayed. Images are 3-mm slice thickness, repetition time $=1 \mathrm{~s}$ and echo time $=30 \mathrm{~ms}$ in both cases.

spectrum measurements of the spring 1999 flushes, which were sprayed with a $n \mathrm{C} 23$ $\mathrm{HMO}$, show that the signals of oil protons at $\delta=1.4$ to $1.8 \mathrm{ppm}$ were detected in all stem segments from the trees applied in the fourteen $0.25 \%$, single $7 \%$, four $1.75 \%$, and fourteen $0.5 \%$ treatments, while such signals were not detected or detected at very low levels in stem segments from the unsprayed trees and the trees sprayed with single $2 \%$ and $3.5 \%$, and double $1.75 \%$ applications. Similar observations were obtained from measurements of the spring 2000 flushes, which were not sprayed with the oil as they were produced 4 to 5 months after the last spray was applied. This indicates that the oil moved to new unsprayed flush growth from oil-sprayed flush growth. Atypical nonselective image of the stem segment of a spring 1999 flush from the single $7 \%$ treatment and the corresponding chemical shift selective image of oil are presented in Fig. 6a and b respectively. Figure $6 \mathrm{~b}$ shows the localization of oil deposits in the outer stem.

\section{Discussion and Conclusions}

In this paper we have demonstrated the feasibility of using chemical shift selective MRI to determine the presence of mineral oil in plants sprayed with a HMO or an AMO. The results indicate the peak resolution and the chemical shift difference in signals of mineral oil in phantom and citrus stems sprayed with
$4 \% \mathrm{v} / \mathrm{v}$ of oil emulsion were adequate for the chemical shift selective imaging of mineral oil. The obvious choice for the selective imaging of mineral oil is by excitation at $\delta \approx 1.3$ to 1.7 $\mathrm{ppm}$, the peaks resulting from resonances of aliphatic protons of the oil. More than $3 \mathrm{ppm}$ chemical shift separation between water and the oil facilitated the differentiation of water and oil in the phantom sample (Fig. 3). The oil was obviously present in a much lower concentration than water in the citrus stems sprayed with $4 \% \mathrm{v} / \mathrm{v}$ AMO oil emulsion, as indicated by the relative signal strengths (Fig. 4), and was consequently more difficult to detect, and required more time to image selectively. With selective excitation at $\delta \approx 1.5 \mathrm{ppm}$, an average of 400 transients was required for each phase -encoding step to produce an acceptable image of the oil. A series of nonselective and selective images of the oil recorded as a function of time after the application of spray, showed the distribution of the oil in the sprayed stems. These experiments demonstrated that AMO molecules penetrated into the stem of citrus seedling shortly after the application of spray, and subsequently moved to the inner tissues. The majority of oil entering the stem tissues remained in the cortex and phloem, while only a small amount of the oil had moved to xylem and pith $10 \mathrm{~d}$ after the oil was applied.

CSSI can be applied for spatial localization of aromatics and carbohydrates as well as water and fat, in suitable plant specimens, with an in-plane resolution down to $15 \mu \mathrm{m}$ and slice thickness less than $250 \mu \mathrm{m}$ (Rumpel and Pope, 1992). However, with the instrumentation available for the present study, this resolution was not achievable. Two factors may have contributed to this observation. Firstly, the relatively lower gradient strengths available in the MRI instrument limit the resolution of images. Secondly, PDSO was at a much lower concentration than water in the plant tissue. Under these circumstances, direct application of chemical shift selective sequence may not produce a clear map of the desired component present at low concentrations in a biological sample with high water content (Tse et al., 1996; Xia and Jelinski, 1995). Extensive signal averaging is necessary to enhance the signal-to-noise ratio (Rumpel and Pope, 1992). It should be noted that several signal-suppression schemes combined with the standard two-dimensional CSSI sequence have been successfully developed to image the spatial distribution of sugar (Tse et al., 1996; Xia and Jelinski, 1995), anethole and oil in a fennel seed (Rumpel and Pope, 1992; Sarafis, 1990), and naturally occurring aromatics and carbohydrates in plant tissues (Pope et al., 1991). In addition, three-dimensional CSSI has been proven to effectively increase resolution of image (Rumpel and Pope, 1992). Further experiments are required to improve the chemical shift selective images of PDSO in plants.

In this study we used MRI to measure deposits of a $92 \%$ UR $n \mathrm{C} 23$ HMO in Washington navel orange trees to which aqueous emulsions with total concentrations of $3.5 \%$ and $7 \%$ of the oil had been applied more than one year before samples were selected for examination. We showed that the deposits of high concentration sprays persisted for longer periods in plant tissues than the deposits of low concentrations, and that oil that entered plant tissues moved from sprayed flushes to unsprayed flushes. Knight et al. (1929) suggested that the impact of saturated $(\geq 98 \%$ UR) oils on plant metabolism may result from the physical intrusion of oil deposits into plant tissue rather than the chemical disruption of cell membranes associated with oxidation of unsaturated and unstable compounds in oils with lower UR values. Our results indicate that long-term persistence of mineral oil in plants may be the main factor contributing to PDSO-induced chronic phytotoxicity.

Quantification of oil deposits has been an interesting topic for horticulturists, plant physiologists, entomologists, plant pathologists, and chemists. Gas chromotography (Furness et al., 1979), Fourier Transform Infra-red (FTIR) (Hodgkinson et al., 1996; Johnson et al., 2002) and fluorescence spectrophotometer (Furness and Newton, 1988) techniques have been developed to quantify the amounts of PDSOs applied to foliage. The results presented in this paper have demonstrated the potential for visualising of the localisation of PDSOs within plants. Further quantitative evaluation of the oil by NMR and MRI is warranted, although this would require knowledge of spatial distribution of relaxation times of the oil (Rumpel et al., 1991).

Finally, despite considerable effort, our attempts to use MRI to detect AMO in leaves were not successful. This was to a large extent due to the intrinsic structure of leaves in which the major component, by a significant margin, is water, and that resonance from comparatively very low concentrations of PDSO is obscured by the higher concentration of water. The deuterium $\left({ }^{2} \mathrm{H}\right)$ MRI technique, which has proven to resolve the spatial structure of plant leaves within $0.03 \mathrm{~mm}$ (Link and Seelig, 1990), may make the chemical shift selective MRI detection of PDSO in leaves feasible.

\section{Literature Cited}

Agnello, A. 2002. Petroleum-derived spray oils: chemistry, history, refining and formulation, p. 2-18. In: G.A.C. Beattie, D.M. Watson, M. Stevens, D.J. Rae, and R.N. Spooner-Hart (eds.). Spray oils beyond 2000. Univ. Western Sydney.

Beattie, G.A.C., D.M. Watson, M.L. Stevens, D.J. Rae, and R.N. Spooner-Hart (eds.). Spray oils beyond 2000. Univ. Western Sydney.

Callaghan, P.T. 1991. Principal of nuclear magnetic resonance microscopy. Clarendon Press, Oxford, U.K.

Chudek, J.A. and G. Hunter. 1997. Magnetic resonance imaging of plants. Progr. Nuclear Magnetic Resonance Spectrosc. 31:43-62.

Davidson, N.A., J.E. Dibble, M.L. Flint, P.J. Marer, and A. Guye. 1991. Managing insects and mites with spray oils. Univ. Calif., Oakland, Publ. 3347.

Gersbach, P.V. and N. Reddy. 2002. Noninvasive localization of Thymol accumulated in Carum copticum (Apiaceae) fruits by chemical shift selective magnetic resonance imaging. Ann. 
Bot. 90:1-5.

Grossman, J. 1990. Horticultural oils: New summer uses on ornamental plant pests. IPM Practitioner 12(8):1-10.

Ebeling, W. 1950. Subtropical entomology. Lithotype Process Co., San Francisco, Calif.

Faust, M., P.C. Wang, and J. Maas. 1997. The use of magnetic resonance imaging in plant science. Hort. Rev. 20:225-266.

Furness, G.O., R.T. Howard, and P.J. Smith. 1979. Measurement of petroleum oil deposit on citrus leaves by gas-liquid chromatography. Pest. Sci. $10: 478-484$

Furness, G.O. and M. Newton. 1988. A leaf surface scanning technique using a fluorescence spectrophotometer for the measurement of spray deposit. Pest. Sci. 24:123-137.

Hodgkinson, M.C., D. Johnson, and G. Smith. 2002. Causes of phytotoxicity induced by petroleumderived spray oil,p. 170-178. In: G.A.C. Beattie, D.M. Watson, M.L. Steven, D.J. Rae, and R.N. Spooner-Hart (eds.). Spray oils beyond 2000. Univ. Western Sydney.

Hodgkinson, M.C., D.S. Sagatys, A.P. Mackey, and G. Smith. 1996. Quantitative FTIR method for determination of mineral oil deposited on plant leaves. J. Agr. Food Chem. 43:Short communication.

Halloin, J.M., T.G. Cooper, E.J. Potchen, and T.E. Thompson. 1993. Proton magnetic resonance imaging of lipid in pecan embryos. J. Amer. Oil Chem. Soc. 70:1259-1262.

Huang, M.D., B.L. Tan, R.Q. Mao, Y.G. Chen, G.A.C. Beattie, D.J. Rae, D.M. Watson, Y.J. Cen, J.C. Quan, M.L. Tang, C.X. Chen, S.T. Xie, Z.H. Zhang, and Q.Y. Yang. 2002. Demonstration of horticultural mineral oil-based citrus IPM programs in China, p. 372-378. In: G.A.C. Beattie, D.M. Watson, M.L. Steven, D.J. Rae, and R.N. Spooner-Hart (eds.). Spray oils beyond 2000. Univ. Western Sydney.

Johnson, D., M.C. Hodgkinson, and D. Joyce. $2002 \mathrm{a}$. Potential effects of petroleum-derived spray oils on abscission, senescence and stress physiology of citrus, p. 185-192. In: G.A.C. Beattie, D.M. Watson, M.L. Steven, D.J. Rae, and R.N. Spooner-Hart (eds.). Spray oils beyond 2000. Univ. Western Sydney.
Johnson, D., M.C. Hodgkinson, and O. Nicetic. 2002 b. Quantification of mineral oil spray deposits on foliage by solvent extraction and FTIR spectroscopy, p. 592-594. In: G.A.C. Beattie, D.M. Watson, M.L. Steven, D.J. Rae, and R.N. Spooner-Hart (eds.). Spray oils beyond 2000. Univ. Western Sydney.

Knight, H., J.C. Chamberlin, and C.D. Samuels. 1929. On some limiting factors in the use of saturated petroleum oils as insecticides. Plant Physiol. 4:299-321.

Link, J. and J. Seelig. 1990. Comparison of deuterium NMR imaging methods and application to plants. J. Magnetic Resonance 89:310-330.

MacFall, J.S., G.A. Johnson, and P.J. Kramer. 1991. Comparative water uptake by roots of different ages in seedling of loblolly pine (Pinus taeda L.). New Phytol. 119:551-560.

Metzler, A., M. Izquierdo, A. Ziegler, W. Kockenberger, E. Komor, M. Von Kienlin, and A. Haase. 1995. Plant histochemistry by correlation peak imaging. Proc. Natl. Acad. Soc. USA 92:11912-11915.

Pope, J.M. 1992. Application of chemical shift microscopy to nondestructive histochemistry of plant materials, p. 441-457. In: B. Blumich and W. Kuhn(eds.). Magnetic resonance microscopy: Methods and application in materials science, agriculture and biomedicine. Wiley-VCH, Weinheim.

Rae, D.J., D.M. Watson, M.D. Huang, Y.J. Cen, B.Z. Wang, G.A.C. Beattie, W.G. Liang, B.L. Tan, and D.G. Liu. 2000. Efficacy and phytotoxicity of multiple petroleum oil sprays on sweet orange (Citrus sinensis L.) and pummelo (C.grandis L.) in southern China. Intl. J. Pest Mgt. 46:125-140

Riehl, L.A. 1969. Advances relevant to narrow-range spray oils for citrus pest control. Proc.1st Intl. Soc. Citricult. Symp., Univ. Calif., Riverside. 2:897-907.

Rohrbaugh, P.W. 1934. Penetration and accumulation of petroleum spray oils in the leaves twigs and fruits of citrus tree. Plant Physiol. 9:699-730

Rohrbaugh, P.W. 1941. Physiological effects of petroleum oil sprays on citrus. J. Econ. Entomol. 34:812-815.

Rollins, A., J. Barber, R. Elliott, and B. Wood. 1989. Xenobiotic monitoring in plants by ${ }^{19} \mathrm{~F}$ and ${ }^{1} \mathrm{H}$ nuclear magnetic resonance imaging and spectroscopy. Plant Physiol. 91:1243-1246.

Rumpel, H. and J.M. Pope. 1992. The application of 3-D chemical shift microscopy to noninvasive histochemistry. Magnetic Resonance Imaging 10:187-194.

Sarafis, V., H. Rumpel, J. Pope, and W. Kuhn. 1990. Noninvasive histochemistry of plant materials by magnetic resonance microscopy. Protoplasma 159:70-73.

Smith, D., G.A.C. Beattie, and R. Broadley. 1997. Citrus pests and their natural enemies: Integrated pest management in Australia. Hort. Res. Dev. Corp., Queensland Dept. Primary Ind., Brisbane.

Tan., B.L. 2004. Phytotoxicity and movement in plants of horticultural and agricultural mineral oils. PhD thesis. Univ. Western Sydney.

Tse., T.Y., R.M. Spanswick, and L.W. Jelinski. 1996. Quantitative evaluation of NMR and MRI methods to measure sucrose concentration in plants. Protoplasma 194:54-62.

Xia, J. and P.T. Callaghan. 1992. "One-shot”velocity microscopy: NMR imaging of motion using a single phase-encoding step. Magnetic Resonance Med. 23:138-53.

Xia, J. and L.W. Jelinski. 1995. Imaging low concentration metabolites in the presence of a large background signal. J. Magnetic Resonance B107:1-9.

Young, P.A. 1934. Penetration, distribution and effect of petroleum oils in apple. J. Agr. Res. 49:559-571.

Young, P.A. 1935. Distribution and effect of petroleum oils and kerosenes in potato, cucumber, turnip, barley and onion. J. Agr. Res. 51:925-934.

Young, P.A. 1941. Physiological and physical effects of spray oils on deciduous trees. J. Econ. Entomol. 34:838-844.

Young, P.A and H.E. Morris. 1933. Injury to apple by petroleum oil sprays. J. Agr. Res. 47:502-512.

Zimmerman, U., J. Rygol, A. Balling, G. Klork, A. Metzler, and A. Hassse. 1992. Radial turgor osmotic pressure profiles in intact and excised roots of Asater tripolium. Plant Physiol. 99:186-96. 